\title{
ADELMANN, Gerhard, Die Baumwollgewerbe Nordwestdeutschlands und der westlichen Nachbarländer beim Übergang von der vorindustriellen zur frühindustriellen Zeit 1750-1815. Verflechtung und regionale Differenzierung
}

\section{Guillaume Garner}

\section{OpenEdition}

\section{Journals}

Édition électronique

URL : http://journals.openedition.org/ifha/1108

DOI : $10.4000 /$ ifha. 1108

ISSN : 2198-8943

Éditeur

IFRA - Institut franco-allemand (sciences historiques et sociales)

Référence électronique

Guillaume Garner, «ADELMANN, Gerhard, Die Baumwollgewerbe Nordwestdeutschlands und der westlichen Nachbarländer beim übergang von der vorindustriellen zur frühindustriellen Zeit 1750-1815. Verflechtung und regionale Differenzierung ", Revue de l'IFHA [En ligne], Date de recension, mis en ligne le 01 janvier 2003, consulté le 22 septembre 2020. URL : http://journals.openedition.org/ifha/1108; DOI : https://doi.org/10.4000/ifha. 1108

Ce document a été généré automatiquement le 22 septembre 2020.

(C)IFHA 


\section{ADELMANN, Gerhard, Die Baumwollgewerbe Nordwestdeutschlands und der westlichen Nachbarländer beim Übergang von der vorindustriellen zur frühindustriellen Zeit 1750-1815. Verflechtung und regionale Differenzierung}

\section{Guillaume Garner}

1 Cet ouvrage est l'édition tardive d'une thèse d'habilitation soutenue en 1970. Le propos de l'auteur était d'étudier la Révolution industrielle dans l'industrie du coton en Allemagne, dans les Provinces-Unies et en Belgique de 1750 à 1815. G.A. divise son étude en trois parties : la première est consacrée à un rappel de « la situation de départ pré-industrielle (1750-1780) » dans l'Europe du nord-ouest, la seconde aux « débuts et [aux] phases de l'industrialisation du secteur cotonnier britannique ", la dernière à l'industrialisation de ce même secteur dans l'Europe du nord-ouest.

2 Reposant sur un imposant travail de dépouillement d'archives dans les trois pays cités, ainsi qu'en France, cette étude fournit un nombre important de données concrètes et quantitatives sur l'évolution des techniques de filage et de tissage ainsi que sur l'organisation de la production et la diffusion des manufactures et des fabriques. Il met en particulier en valeur la continuité existant entre anciens et nouveaux centres de filage du coton, ces derniers étant apparus à partir des années 1780 au sein de régions industrielles déjà établies. 
3 L'ouvrage n'ayant pas été mis à jour (un simple coup d'œil sur la bibliographie permet de le constater), il est donc très daté dans son approche des réalités industrielles de l'Europe occidentale à la fin du XVIIIe et au début du XIXe s. Il reprend la vision répandue d'une " avance " acquise à partir des années 1750 par l'Angleterre sur l'Europe continentale, vision qui suppose implicitement l'existence d'un modèle unique («britannique ») d'industrialisation, idée que les travaux de P. Kriedte, H. Medick, J. Schlumbohm ou, plus récemment, de P. Verley (pour ne citer que quelques noms) ont contribué à abandonner. L'industrialisation est par ailleurs largement abordée comme un ensemble de processus et de phénomènes d'ordre technique, cette approche se situant dans la continuité de celle développée par D.S. Landes. Les aspects sociaux sont certes étudiés par G.A. (à travers des données sur la répartition de la main-d'œuvre), mais le rôle joué par les circuits de commercialisation et par la sphère de la demande est, comme c'était le cas il y a une trentaine d'années, négligé.

4 Ces remarques ne sont en rien des critiques portées contre la qualité de cette étude ; elles suggèrent simplement que l'intérêt de celle-ci est peut-être autant d'ordre historiographique qu'historique.

Guillaume GARNER 